\title{
Ulcerative colitis and Crohn's disease: a comparison of the colorectal cancer risk in extensive colitis
}

\author{
C D Gillen, R S Walmsley, P Prior, H A Andrews, R N Allan
}

\begin{abstract}
The risk of developing colorectal cancer has been compared in two identically selected cohorts of patients with extensive Crohn's colitis $(n=125)$ and extensive ulcerative colitis $(n=486)$. In both groups the effects of selection bias have been reduced wherever possible. There was an 18-fold increase in the risk of developing colorectal cancer in extensive Crohn's colitis and a 19-fold increase in risk in extensive ulcerative colitis when compared with the general population, matched for age, sex, and years at risk. The absolute cumulative frequency of risk for developing colorectal cancer in extensive colitis was $8 \%$ at 22 years from onset of symptoms in the Crohn's disease group and $7 \%$ at 20 years from onset in the ulcerative colitis group. The relative risk of colorectal cancer was increased in both ulcerative colitis and Crohn's disease among those patients whose colitis started before the age of 25 years. Whether the absolute risk is greater in the younger age group or merely reflects that the expected number of carcinomas increases with age is uncertain. While there is an increased risk of developing colorectal cancer in extensive colitis the number of patients with Crohn's disease who actually develop colorectal cancer is small because many patients with extensive Crohn's colitis undergo colectomy early in the course of their disease to relieve persistent symptoms unresponsive to medical treatment.
\end{abstract}

(Gut 1994; 35: 1590-1592)

Patients with ulcerative colitis have an increased risk of developing colorectal cancer when compared with the general population ${ }^{1}$ and the excess risk is almost entirely confined to patients with longstanding extensive colitis. ${ }^{2}$ Although population based studies are the preferred epidemiological method for determining the colorectal cancer incidence in ulcerative colitis we have shown that the incidence of colorectal cancer in ulcerative colitis can be estimated by studying a cohort of hospital patients, after reducing the effects of bias whenever possible inherent in any hospital based study. ${ }^{4}$ The cancer risk in Crohn's disease is less well defined. Several statistical studies have shown an increased risk of colorectal cancer in Crohn's disease. ${ }^{5-8}$ Three have found no such association, ${ }^{9-11}$ but this lack of association might be explained by short follow up, ${ }^{9}$ a large proportion of patients undergoing panproctocolectomy for symptomatic colitis, ${ }^{10}$ or small numbers of patients with short follow up. ${ }^{11}$ In this study of patients with extensive colitis we have, for the first time, compared the colorectal cancer risk in Crohn's disease with the risk in an identically selected series of patients with ulcerative colitis. ${ }^{4}$

\section{Methods}

\section{CROHN'S DISEASE COHORT}

A total of 281 patients were selected for this study from among those first seen at the General and Queen Elizabeth Hospitals, Birmingham between 1945-1975. The patients were selected if they were resident in the West Midlands region, were 15 or more years of age, and within five years of onset of symptoms when first seen at the index centre. A total of 5213 patient years at risk (PYR) was observed for all patients (mean 20.2 years from onset). When this cohort was divided by extent of colitis there were 125 patients $(44.5 \%)$ with extensive Crohn's colitis. These data formed the basis of our study of the colorectal cancer risk in Crohn's disease. ${ }^{12}$ Extensive colitis was defined as disease involving the whole colon as far proximally as the hepatic flexure and total colitis as colitis involving all the large intestine including the ascending colon.

\section{ULCERATIVE COLITIS COHORT}

A total of 823 patients were initially included in this study from among those first seen at one of three centres (Birmingham, Oxford, Stockholm county). ${ }^{4}$ All patients were resident in a strictly defined geographical area, and when first seen at the index centre were 15 or more years of age and were within five years of symptomatic onset of ulcerative colitis. A total of 16928 PYR was observed for all patients (mean 20.5 years from onset). Among these patients 486 (59\%) had extensive colitis.

\section{COMPUTATION}

The number of cancers expected to occur was computed using the person years programme (PYRS). ${ }^{13}$ The procedure applied age, sex, and site specific cancer incidence rates, derived from data from the Regional Cancer Registry, applicable to each subgroup, to age and sex \\ Queen Elizabeth
Hospital, Birmingham \\ C D Gillen \\ H A Andrews \\ Cancer Epidem \\ University of \\ Birmingham, \\ February 1994
}


TABLE I Extensive colitis: colorectal cancer morbidity 5+ years from onset (corrected for operation)

\begin{tabular}{lllllr}
\hline & Site & $O$ & $E$ & $\begin{array}{l}\text { Relative } \\
\text { risk }\end{array}$ & $\begin{array}{l}\text { 95\% Confidence } \\
\text { intervals }\end{array}$ \\
\hline Ulcerative colitis & Colon & 22 & $0 \cdot 90$ & $24 \cdot 4^{\star \star \star}$ & $15 \cdot 3$ to $37 \cdot 0$ \\
$(\mathrm{n}=486)$ & Rectum & 7 & $0 \cdot 61$ & $11 \cdot 5^{\star \star \star}$ & $4 \cdot 6$ to $23 \cdot 6$ \\
Crohn's disease & Total & 29 & $1 \cdot 51$ & $19 \cdot 2^{\star \star \star}$ & $12 \cdot 9$ to $27 \cdot 5$ \\
$(\mathrm{n}=125)$ & Colon & 6 & $0 \cdot 16$ & $37 \cdot 5^{\star \star \star}$ & $13 \cdot 7$ to $81 \cdot 6$ \\
& Rectum & 2 & $0 \cdot 28$ & $7 \cdot 1^{\star}$ & $0 \cdot 8$ to $25 \cdot 8$ \\
& Total & 8 & $0 \cdot 44$ & $18 \cdot 2^{\star \star \star}$ & $7 \cdot 8$ to $35 \cdot 8$ \\
\hline
\end{tabular}

$\mathrm{O}=$ observed cancers, $\mathrm{E}=$ expected cancers. ${ }^{\star} \mathrm{p}<0 \cdot 05,{ }^{\star \star \star} \mathrm{p}<0 \cdot 001$

specific years at risk (PYR). For sites of cancer other than large bowel, PYR were accumulated to date of death or to the end of the study periods for survivors. PYR were truncated at the date when total colectomy or proctectomy, or both, had been completed to compute expected numbers for colon and rectum respectively. The results for 'all sites of cancer' were then modified to allow for the effect of this truncation on the estimates of expected cancers.

\section{STATISTICAL TESTING}

The relative risk of cancer (RR) is defined as the observed/expected number, the risk being relative to that of the general population. The significance of the difference between the RR and 1.0 was assessed by assuming that the observed number followed a Poisson distribution, with a mean equal to the expected number. Exact Poisson probabilities were computed for a one tailed significance test. The method of Rothman and Boice ${ }^{14}$ was used to obtain $95 \%$ confidence intervals $(95 \% \mathrm{CI})$ for the RRs. Estimates of cumulative risk of colorectal cancer were computed by the product limit method (Kaplan and Meier). ${ }^{15}$

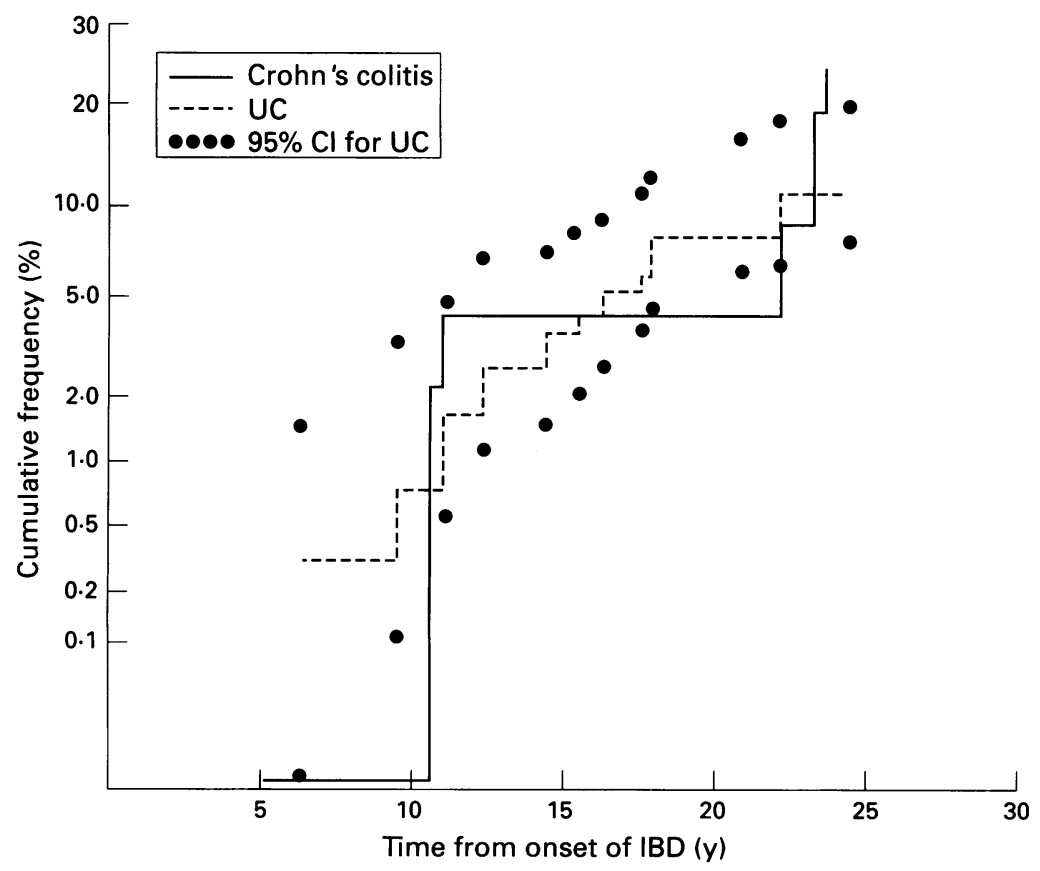

The cumulative frequency of colorectal cancer in patients with extensive ulcerative colitis (UC) and extensive Crohn's colitis.

\section{Results}

EXTENSIVE COLITIS: COLORECTAL CANCER MORBIDITY, ALL PATIENTS, 5+ YEARS FROM ONSET (CORRECTED FOR OPERATION)

Extensive ulcerative colitis - the 29 colorectal cancers ( 22 colonic, 7 rectal) represent a highly significant 19-fold excess when assessed against the expectation for the whole series. Rectal carcinoma was only seen in those patients with extensive ulcerative colitis $(0=29, \mathrm{E}=1.51, \mathrm{RR}=19 \cdot 2, \mathrm{p}<0.001)$.

Extensive Crohn's colitis - colorectal cancers were only found in patients with extensive colitis. The eight colorectal cancers ( 6 colonic, 2 rectal) represent a highly significant 18 -fold excess which is similar to the risk in patients with extensive ulcerative colitis $(0=8, \mathrm{E}=0 \cdot 44$, $\mathrm{RR}=18 \cdot 2, \mathrm{p}<0 \cdot 001)$. Inevitably, given the small numbers of patients studied the $95 \% \mathrm{CI}$ are wide (Table I).

\section{CUMULATIVE FREQUENCY OF COLORECTAL CANCERS}

The absolute cumulative frequency of colorectal cancer in patients with extensive colitis was $8 \%$ at 22 years from onset in the patients with Crohn's disease and $7 \%$ at 20 years from onset in the patients with ulcerative colitis (Figure).

\section{RELATIVE RISK AND AGE AT ONSET}

The relative risk of colorectal cancer was considerably increased in both ulcerative colitis and Crohn's disease among those patients whose colitis started before the age of 25 years (Table II).

\section{Discussion}

Effective comparison of the cancer risk in Crohn's disease and ulcerative colitis is difficult because the extent of macroscopic disease in the two disorders is often so different. As the excess colorectal cancer risk in ulcerative colitis is, however, largely confined to patients with extensive or total colitis and the observed pattern is similar in Crohn's disease (apart from a small excess in the small intestine) it seemed appropriate to compare the colorectal cancer risk in these two groups. While a population based group of patients provides the ideal basis for such a study, in practice such series are rarely available and their value limited by short follow up.

We have already shown that once the known biases in a hospital series have been reduced wherever possible, the colorectal cancer risk in a hospital based series is similar to that in a population based group of patients with ulcerative colitis. ${ }^{4}$ In this study we therefore compared the colorectal cancer risk in extensive or total ulcerative colitis, using the data from three centres (Birmingham, Oxford, and Stockholm) with the risk of extensive or total Crohn's colitis from the Birmingham series. $^{12}$ Ideally we would have liked to increase the size of the cohort of patients 
TABLE II Extensive colitis: cancer of the large bowel by age at onset of ulcerative colitis and Crohn's disease, 5+ years after onset (corrected for operation)

\begin{tabular}{lcclll}
\hline & Age group & $O$ & $E$ & $\begin{array}{l}\text { Relative } \\
\text { risk }\end{array}$ & $\begin{array}{l}\text { 95\% Confidence } \\
\text { intervals }\end{array}$ \\
\hline Ulcerative colitis & $<25$ & 12 & $0 \cdot 11$ & $109 \cdot 1^{\star \star \star}$ & $\begin{array}{l}56 \cdot 3 \text { to } 190 \cdot 6 \\
\end{array}$ \\
Total & $25-39$ & 14 & $0 \cdot 50$ & $28 \cdot 0^{\star \star \star}$ & $15 \cdot 3$ to $47 \cdot 0$ \\
Crohn's disease & $40+$ & 3 & $0 \cdot 90$ & $3 \cdot 33$ & $0 \cdot 7$ to $9 \cdot 7$ \\
& $<25$ & 29 & $1 \cdot 51$ & $19 \cdot 2^{\star \star \star}$ & $12 \cdot 9$ to $27 \cdot 6$ \\
Total & $25-39$ & 4 & $0 \cdot 07$ & $57 \cdot 1^{\star \star \star}$ & $15 \cdot 4$ to $146 \cdot 3$ \\
& $40+$ & 2 & $0 \cdot 22$ & $9 \cdot 1^{\star \star}$ & $1 \cdot 0$ to $32 \cdot 8$ \\
& & 8 & $0 \cdot 15$ & $13 \cdot 3$ & $1 \cdot 5$ to $48 \cdot 1$ \\
\hline
\end{tabular}

${ }^{\star \star} \mathrm{p}<0 \cdot 01,{ }^{\star \star \star} \mathrm{p}<0 \cdot 001$. Abbreviations as in Table I.

with extensive Crohn's colitis, but it proved difficult to obtain complete data from the other two centres.

The same criteria were used to define the patient cohorts to ensure a valid comparison; that is patients over 15 years of age at onset of symptoms drawn from a defined geographical area and seen within five years of onset of symptoms. The completeness of follow up was $97 \%$ in the patients with ulcerative colitis and $100 \%$ in the patients with Crohn's disease. The relative risk of developing colorectal cancer is remarkably similar in the two groups when compared with the general population, corrected for age, sex, and years of follow up. The cumulative risk over time in patients with extensive ulcerative colitis and Crohn's disease is also similar. The relative rectal sparing, seen in Crohn's disease, has not reduced the risk of developing colorectal cancer in Crohn's disease. Inevitably, given the relatively small numbers the confidence intervals in the Crohn's disease study are relatively wide. An even larger study would be required to reduce the confidence intervals in the group of patients with Crohn's disease.

While a statistically significant trend over age could not be shown either for ulcerative colitis or Crohn's disease when age band was used as a stratifying variable in the product limit analysis or in a Cox regression analysis, the absolute risk is broadly the same. Age at onset of the underlying colitis as an independent risk factor for the development of colorectal cancer, however, has also been suggested by earlier studies in both Crohn's disease $^{58}$ and ulcerative colitis. ${ }^{16}$ Whether the absolute risk is greater in the younger age group or merely reflects that the expected number of carcinomas increases with age is uncertain. If the relative risk is a measure of association between Crohn's disease and cancer, then the high relative risk in young people could be interpreted to mean that most cancers at this age are associated with Crohn's disease, whereas in older age groups a smaller proportion of incident cancers can be attributed to the association.
Stahl et al have suggested that younger patients with Crohn's disease should be considered for colonic surveillance to permit earlier diagnosis and treatment of colorectal cancer. ${ }^{17}$ The number of patients with Crohn's disease developing colorectal cancer is small, however, as many patients with extensive Crohn's colitis required colectomy to relieve persistent symptomatic disease early in the course of their illness, thus eliminating the colorectal cancer risk. It would be difficult to justify a surveillance policy for all patients with extensive or total Crohn's colitis, particularly as the value of surveillance for colorectal cancer in ulcerative colitis has been questioned recently. ${ }^{1819}$ The data presented here suggest that it might be sensible to consider a surveillance programme for those few patients with extensive colitis of long standing with an intact colon whose Crohn's disease started at a young age.

The authors are grateful for the generous financial support from the Cancer Research Campaign and the National Association for Colitis and Crohn's Disease.

1 Butt JH, Lennard-Jones JE, Ritchie JK. A practical approach to the risk of cancer in inflammatory bowel disease. Med Clin North Am 1980; 64: 1203-20.

2 Kewenter J, Ahlman H, Hulten L. Cancer risk in extensive colitis. Ann Surg 1978; 188: 824-7.

3 Hendriksen C, Kreiner S, Binder V. Long term prognosis in ulcerative colitis - based on results from a regional patient group from the county of Copenhagen. Gut 1985; 26: 58-63.

4 Gyde SN, Prior P, Allan RN, et al. Colorectal cancer in ulcerative colitis: a cohort study of primary referrals from three centres. Gut 1988; 29: 206-17.

5 Weedon DD, Shorter RG, Ilstrup DM, et al. Crohn's disease and cancer. N Engl f Med 1973; 289: 1099-103.

6 Greenstein AI, Sachar DB. Cancer in Crohn's disease. In Allan RN, Keighley MRB, Alexander-Williams J, Hawkins CF, eds. Inflammatory bowel diseases. Edinburgh: Churchill Livingstone, 1983: 332-7.

7 Greenstein AJ, Sachar DB, Smith H, et al. A comparison of cancer risk in Crohn's disease and ulcerative colitis. Cancer 1981; 48: 2742-5.

8 Ekbom A, Helmick C, Zack M, Hans-Olov A. Increased risk of large bowel cancer in Crohn's disease with colonic involvement. Lancet 1990; 336: 357-9.

9 Binder V, Hendriksen C, Kreiner S. Prognosis in Crohn's disease - based on results from a regional patient group from the county of Copenhagen. Gut 1985; 26: 146-50

10 Kvist N, Jacobsen $\mathrm{O}$, Norgaard $\mathrm{P}$, et al. Malignancy in Crohn's disease. Scand $\mathcal{f}$ Gastroenterol 1986; 21: 82-6.

11 Gollop JH, Phillips SF, Melton LJ III, Zinsmeister AR. Epidemiologic aspects of Crohn's disease. Gut 1988; 29: 49-56.

12 Gillen CD, Andrews HA, Prior P, Allan RN. Crohn's disease and colorectal cancer. Gut 1994; 35: 651-6.

13 Coleman M, Douglas A, Hermon C, Peto J. Cohort study analysis with a FORTRAN computer program. Int $\mathcal{f}$ Epidemiol 1986; 15: 134-7.

14 Rothman KT, Boice JD Jr. Epidemiologic analysis with a programmable calculator. NIH Publication No 79-1649. grammable calculator. NIH Publication No 79-1649.

15 Kaplan EL, Meier P. Non-parametric estimates from incomplete observations. Am Stat Assoc ff 1958; 10: 457-81.

16 Ekbom A, Helmick C, Zack M, Adami HO. Ulcerative colitis and colorectal cancer. A population based study. N Engl ₹ Med 1990; 323: 1228-33.

17 Stahl TJ, Schoetz DJ Jr, Roberts PL, et al. Crohn's disease and carcinoma: increasing justification for surveillance? Dis Colon Rectum 1992; 35: 850-6.

18 Collins RH, Feldman M, Fordran JS. Colon cancer, dysplasia and surveillance in patients with ulcerative colitis: sia and surveillance in patients with ulcerative

19 Gyde SN. Screening for colorectal cancer in ulcerative colitis: dubious benefits and high costs. Gut 1990; 31: 1089-92. 